\title{
Shallow and Deep Current Variability in the Southwestern Japan/East Sea
}

\author{
D. Randolph Watts \\ Graduate School of Oceanography \\ University of Rhode Island \\ South Ferry Road \\ Narragansett, RI 02882-1197 \\ phone:(401) 874-6507 fax: (401) 874-6728 email: rwatts@gso.uri.edu \\ Mark Wimbush \\ Graduate School of Oceanography \\ University of Rhode Island \\ South Ferry Road \\ Narragansett, RI 02882-1197 \\ phone: (401) 874-6515 fax: (401) 874-6728 email: mwimbush@gso.uri.edu \\ William Teague \\ Naval Research Laboratory \\ Stennis Space Center \\ MS 39529-5004 \\ phone: (228) 688-4734 fax: (228) 688-5997 email: wteague@nrlssc.navy.mil \\ Zachariah Hallock \\ Naval Research Laboratory \\ Stennis Space Center \\ MS 39529-5004 \\ phone: (288) 688-5242 fax: (288) 688-5997 email: zhallock@nrlssc.navy.mil \\ Award Number: N000149810246 and N0001400WX20337 \\ http://sam.ucsd.edu/onr_jes/onr_jes.html \\ http://po.gso.uri.edu/dynamics/jes/index.html
}

\section{LONG-TERM GOALS}

We seek to understand the physics of the mesoscale circulation in the Japan/East Sea, with our efforts focusing on the southwestern region where the variability is especially energetic.

\section{OBJECTIVES}

(1) To observe the time-varying transports of the three branches of the Tsushima Current in the Ulleung Basin. From the observations, we will produce daily maps of the upper layer circulation and path variability of the Offshore Branch and East Korean Warm Current, with mesoscale resolution.

(2) To understand the physical coupling between the shallow and deep currents and eddies within this region, where large-amplitude meanders and steep loop formations occur. 
(3) To quantify cross-frontal and vertical fluxes associated with mesoscale processes in the East Korean Warm Current.

\section{APPROACH}

A two-dimensional array of 25 pressure-gauge-equipped inverted echo sounders (PIES) was deployed in the Ulleung Basin, which covers roughly a $250-\mathrm{km}$ square region between Korea and Japan. To level the pressure measurements, we also deployed 13 current-meter moorings (CM). These moorings augmented a set of 4 moorings deployed by the Korean Ocean Research and Development Institute (KORDI, Dr. M.-S. Suk) and an additional mooring installed by the Research Institute for Applied Mechanics at Kyushu University (RIAM, Dr. J.-H. Yoon). The combined array is shown in Figure 1. These instruments will provide two-year time series of dynamic height, vertical shear, and deep current fields, enabling us to map the upper and deep absolute current structure on a daily basis.

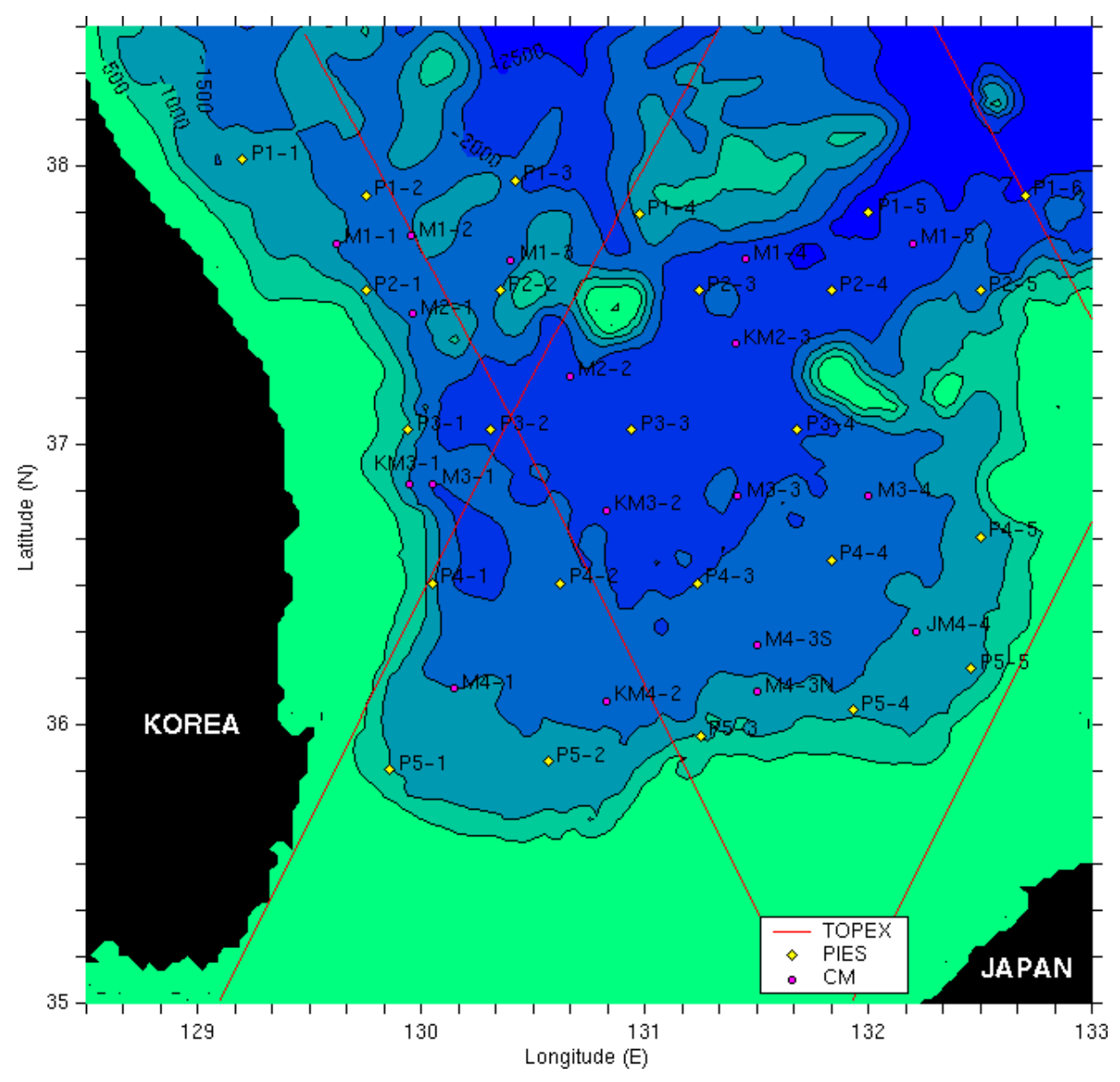

Figure 1. The moored array in the Ulleung Basin of the Japan / East Sea. Yellow diamonds designate PIES sites $(\mathrm{P} \Theta-\Theta)$ and magenta dots designate CM sites (labeled M $\Theta-\Theta$ for URI sites, $K M \Theta-\Theta$ for KORDI sites, JM $\Theta-\Theta$ for RIAM site). TOPEX / POSEIDON altimeter ground tracks are indicated by the red lines. Bottom depths are color-coded with shallow depths indicated by green, and deeper depths by hues of blue; bathymetric contours are labeled in meters. The eastern portion of the Korean Peninsula is on the left, and a segment of Honshu, Japan is at the lower right. 


\section{WORK COMPLETED}

A large fraction of the instrumentation used in the field program was already available. However, a DURIP award provided the necessary funding to purchase the additional equipment needed to conduct the full field program.

In June 1999, a 2-week cruise aboard the R/V Roger Revelle was conducted to deploy the moored instrumentation. An expendable bathythermograph XBT was launched at each PIES site after its deployment to provide calibration information. We also carried out three test deployments of a new model PIES.

It was particularly important to coordinate our instrument positions with Korean deep-crab fishing captains. There is intense fishing and crabbing in the Ulleung Basin, including bottom fishing at depths as great as 2,000 meters. KORDI scientists, led by Dr. Moon-Sik Suk, kindly arranged a meeting with the fishing captains' union in order to minimize potential interferences between the activities of our two groups. During the cruise when we encountered concerned fishermen in their boats, Dr. Suk was able to conduct on-site negotiations to allay their fears or to reposition moorings when necessary. After the cruise, diagrams of the instruments and their positions were supplied to the fishing captains. At six-month intervals, prior to each March/September intensified interval of crab fishing, we have sent reminder communications to the captains via KORDI. Recovery of this array is planned for June-July 2001.

To assist in analyzing the recorded time series following instrument recovery, we have been using historical hydrographic data from the Ulleung Basin region to calculate Gravest Empirical Modes (GEMs), relating acoustic echo time to profiles of temperature $T$, specific volume anomaly $\delta$, and other variables.

We have also investigated the performance of the Modular Ocean Data Assimilation System (MODAS) in the Japan/East Sea, by comparing the MODAS static climatology with Levitus and GDEM climatologies, and by comparing the MODAS dynamic temperature and salinity fields (combining static MODAS and inferred corrections from satellite SSH and SST measurements) with those measured by Dr. Craig Lee using SeaSoar.

\section{RESULTS}

We have achieved good results using MODAS climatology to remove the mean seasonal signals before computing (or applying) the GEMs. By this technique we can infer more than $92.5 \%$ of the total variance in $T$ and $\delta$ from PIES echo-time measurements. Figure 2 displays the $T$ GEM together with $T$ standard deviation profiles showing the degree to which MODAS alone and MODAS+GEM allow us to infer, from measured acoustic echo time in the Ulleung Basin, $T$ as a function of depth. Douglas Mitchell, a graduate student conducting his $\mathrm{PhD}$ research on this project with support of a DOD fellowship, will be presenting these results at the "Oceanography of the Western Pacific Marginal Seas” session of the Fall 2000 American Geophysical Union meeting (cited below).

The GEMs which we are computing will constitute the basis of our techniques for interpreting the PIES data after the instruments are recovered. An essential task in preparation for interpreting the PIES data is to develop from historical hydrographic data a set of look-up tables specific to the region 
(Ulleung Basin) — GEM fields - which we can use to estimate, from our PIES measurements, the temperature, density, and velocity structures in the water column.
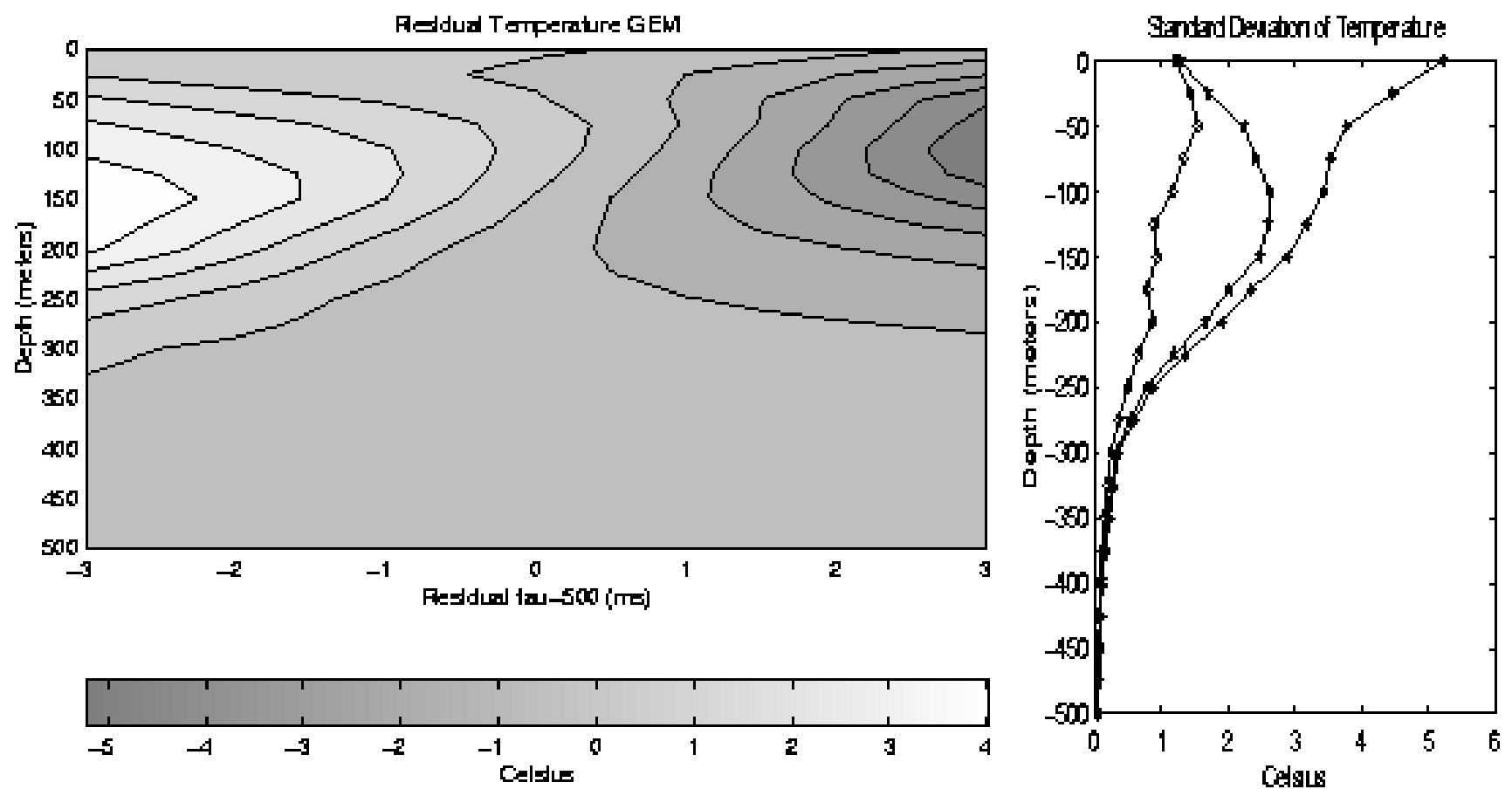

Figure 2. GEM analysis results from 1300 historical hydrographic profiles from the Ulleung Basin. Left panel shows the MODAS-residual GEM field of temperature (T) as a function of acoustic echo time and depth. Right panel shows vertical profiles of $T$ standard deviation ( $P$-right trace), and of $T$ residual standard deviation when MODAS is used alone ( $K$-center trace,) and the substantially smaller uncertainty when MODAS is combined with the GEM ( $\diamond$-left trace).

In the Japan/East Sea, the MODAS static climatology was found to be comparable in quality to the Levitus climatology but with increased horizontal resolution. By comparison with the SeaSoar measured temperature and salinity fields, it was determined that dynamic MODAS portrays real dayto-day ocean conditions in the region far better than a static climatology. A paper (cited below) describing the procedures used in the construction of the MODAS fields and the results of these comparisons has been submitted for publication.

Testing of the new model PIES verified successful performance of the acoustic command system and pulse-delay data-telemetry method. At-sea testing at a variety of depths has continued on cruises unrelated to this project.

\section{IMPACT / APPLICATION}

We expect our data to map the time-dependent meandering of fronts in the Ulleung Basin. They will be used not only to address the above scientific objectives, but also to verify Japan/East Sea numerical models, such as those being developed at NRL. At a later stage, we anticipate that our data will be assimilated into these models. 


\section{TRANSITIONS}

German and Japanese scientists are using arrays of the new model PIES for research in the Denmark Strait and the Kuroshio in the East China Sea, respectively. In addition, Japanese scientists are planning to collaborate with us in deploying a large array of these instruments in the Kuroshio Extension.

\section{RELATED PROJECTS}

Dr. Lynne Talley (SIO) has collected surface-to-bottom hydrographic measurements throughout the Japan/East Sea, and at our PIES sites in particular. These data will be used in conjunction with available historical hydrographic data to produce vertical profiles of temperature, salinity, and specific volume anomaly as functions of acoustic travel time to interpret our PIES measurements .

Dr. Craig Lee made SeaSoar tows coordinated to study the meandering front within our mapping array. We will collaborate on a case study of the 3-D fields of motion and density, and diagnose cross-frontal and vertical motions.

Dr. Hank Perkins et al. made continuous current measurements using bottom mounted Acoustic Doppler Current Profilers made across the Korea-Tsushima Strait between May 1999 and March 2000, as part of NRL's Linkages of Asian Marginal Seas (LINKS) program. The current which enters the Japan Sea and our PIES region from the Korea Strait is marked by strong spatial variability, and in the mean consists of two streams, one on each side of the Strait. Between the two streams is a regime of highly variable flow with a weak mean, presumably the wake from Tsushima Island. Mean transport from the Strait into the Japan Sea is approximately 3.3 Sv. Two papers (referenced below) that describe the flow through the Korea Strait have been accepted for publication. These measurements overlay the first nine months of our PIES/CM deployment and will be utilized in our analysis of the current field, extending our analysis from the Southwestern Japan Sea into the Korea Strait.

\section{REFERENCES}

Jacobs, G.A., H.T. Perkins, W.J. Teague, and P.J. Hogan, 2000: Summer Transport through the KoreaTsushima Strait, Journal of Geophysical Research, In press.

Perkins, H.T., W.J. Teague, G.A. Jacobs, K.I. Chang, and M.-S. Suk, 2000: Currents in KoreaTsushima Strait during summer 1999, Geophysical Research Letters, In press.

\section{PUBLICATIONS}

Fox, D.N., W.J. Teague, C.N. Barron, M.R. Carnes, and C.M. Lee. 2000: The Modular Ocean Data Assimilation System (MODAS), Journal of Atmospheric and Oceanic Technology, Submitted.

Mitchell, D.A., W.J. Teague, D.R. Watts, and M. Wimbush, 2000: Gravest Empirical Modes determined from historical hydrographic observations in the southwestern Japan/East Sea. EOS Transactions American Geophysical Union, Fall 2000 Meeting, Abstracts. 